\title{
Variability of Language Use in the Modern Linguistic Paradigm: Modeling of Discourse Intercultural Communication in the Context of Globalization
}

\author{
Zhibek K. Issayeva ${ }^{1}$, Irina S. Karabulatova ${ }^{2, *}$, Anastasia A. Popova ${ }^{3}$, Natalia V. \\ Dubinina $^{2}$, Abudusalamu Niiiati ${ }^{4}$
}

\author{
${ }^{1}$ National Academy of Education named after Y. Altynsarin of the Ministry of Education and Science of the Republic of \\ Kazakhstan, Astana, Kazakhstan \\ ${ }^{2}$ Russian Academy of Natural Sciences; Department of Foreign Languages, Philological Faculty, Peoples' Friendship \\ University of Russia (RUDN-university), Moscow, Russia \\ ${ }^{3}$ Department of Philosophy and Sociology, Adyghe State University, Maikop, Adygea \\ ${ }^{4}$ Department of Russian Language as Foreign Language, Peoples' Friendship University of Russia (RUDN-university), \\ Moscow, Russia \\ * Corresponding author. Email: radogost2000@mail.ru
}

\begin{abstract}
Personality development, and accordingly, increasing professional competence occurs as the special activities become more complex, in the course of discourse different types of knowledge interact and a concept is formed as a combination of all types of special knowledge (from naive and ordinary ideas to scientific concepts). Since the knowledge of the special sphere is cumulative, it is possible to talk about the stratification of the concept and the development of various fragments of knowledge in different types of discourse.

On this basis, intercultural communication can be viewed as verbally mediated activity, involving the interaction of communicants belonging to different cultures and having different levels of professional competence.

An important prerequisite for a qualitatively new understanding of the phenomenon of intercultural communication is the anthropocentric paradigm of modern linguistics.

In modern theories, intercultural interaction is interpreted as an activity and is a dynamic system of interactions between the subject and the world, the unity of internal (conceptualization and categorization) and external (objectivity of a special sphere) activities, involves the development of personality as a subject of activity, has a transformative character (spreading the world and objectification of man in it), accompanied by the development of spiritual and material culture. In other words, in the process of activity there are many cultural codes, one of which is language.

Based on this, we consider intercultural communication as a verbally mediated activity involving the interaction of communicants belonging to different cultures and possessing different levels of professional competence.

We proceed from the hypothesis: the type of discourse determines the specifics of the nomination of the parameters of the subject, place and time of the event of intercultural communication; the Trend is in the dynamics from interpersonal identity of the individual to social identity in the formation of intercultural competence, from ordinary locally-centered activities towards the temporality of professional activity, as well as increasing the abstraction of localization and time.

The objectives of this work is to consider intercultural communication modeling and simulation methods discourse (as from literature review it is known that at the moment the conventional model of intercultural communication discourse does not exist); justify the proposed model of intercultural communication discourse based on the criteria of personal professional development and intercultural competence of a person, and also to analyze the discourse of intercultural communication to confirm / disprove postulated model is allocated to the factors of the model elements.
\end{abstract}

Keywords: intercultural communication, linguistic, globalization, language processes, discourse of intercultural communication, intercultural competence of the person

\section{INTRODUCTION}

In modern theories, intercultural interaction is interpreted as an activity and is a dynamic system of interaction of the subject with the world, the unity of the internal (conceptualization and categorization) and external (objectivity of the special sphere) activity, involves the development of the individual as a subject of activity, is transformative in it), accompanied by the development of spiritual and material culture. In other words, in the process of activity, a variety of cultural codes arise, one of which is language. 
The one-sidedness of materialistic methodology is associated with its belonging to the paradigm of being, which is clearly outdated. In the development of philosophy, as Habermas writes, it is possible to distinguish three paradigms - the philosophy of being, the paradigm of consciousness and the paradigm of language. The philosophy of being considered knowledge as a reflection of being, the paradigm of consciousness or subject was the understanding of human consciousness as a source of knowledge. In the second half of the 20th century, a new philosophical paradigm was formed - linguistic. The word is no longer understood as a means of expressing the results of thinking, thinking and using language have become understood as coinciding processes. Therefore, there is a change in the paradigm of the subject by the philosophy of intersubjectivity. The basis of the linguistic paradigm was laid by the studies of J. R. Austin and J. L. Searle (1969). John Austin (1962) in his work Word as Action, was the first in philosophy to consider speech not as a means of transmitting information, but as an action that changes the state of the external world. Speech as an action changes not the physical world, but the social world. Language affects social interpersonal relationships, changing social, including legal, facts [1, 2]. Before Austin, philosophers believed that human speech serves to describe phenomena, actions. Meanwhile, there are statements that do not describe events, but carry out actions. Such statements by J. Austin call performative, they can be characterized as successful or unsuccessful (oral deal, promise). But if you examine not the construction of sentences, but the situations of communication, then all words are actions. The theory of speech acts was the basis of the theory of communicative action, developed by Jürgen Habermas and Karl-Otto Apel $[3,4]$. This philosophical concept is able, in our opinion, to most fully uncover the processes of modern society. The act and the speech cannot be reduced, according to Habermas, to activities aimed at achieving the goal, for example, to work. In addition to goal-oriented work, there are communicative actions connected by speech acts and mutual expectation: "By" work "or by goal-action actions I mean either an instrumental action, or a rational choice, or a combination of them. An instrumental action follows technical rules based on empirical knowledge ... By "interaction," on the other hand, I understand the communicative action, symbolic interaction. It is guided by binding consensual norms that define mutual expectations regarding behavior and which must be understood and recognized by at least two actors, while the significance of technical rules and strategies depends on the significance of empirically true or analytically correct statements, the significance of social norms is based only on the intersubjectivity of mutual understanding of intentions and secured by general acceptance of obligations" [5]. Communicative interaction is governed by social norms, which cannot be considered derivatives of labour activity. From the point of view of a communicative theory, historical changes in society should be viewed as two processes unreducible to each other: a change in goalrational activity and the development of forms of communicative interaction. The modern welfare state actively regulates the economy by law, which is no longer a derived super structural phenomenon.

Therefore, the "basis and superstructure" scheme does not reflect all the causes of social changes, contradictions arising in law. It becomes obvious that not only and not so much economic interests give rise to these contradictions. For example, in his Theory of Communicative Action, J.
Habermas indicates that in developed Western societies in recent decades, social conflicts have arisen that differ significantly from traditional for capitalism conflicts related to the distribution of economic benefits. They are no longer formed in the field of material reproduction and are not catalysed by political parties; rather, they arise in the areas of cultural reproduction, social integration and socialization and are developed in pre-institutional forms. They actually reflect the coverage of communicatively structured areas of action: "new conflicts erupt not in the area of distributional problems, but in connection with questions of the grammar of life forms." In modern society, there are such negative phenomena as the alienation of a person from power, an excess of rights that are associated with the expansion of positive law in the areas of traditional regulation by other social norms. The fulfilment by the state of a social function is a necessary condition for alleviating the severity of economic social contradictions, but legal regulation of many social relations becomes inevitable.

Browsing and selecting computer texts is carried out every minute by millions of users using browsers (in English, to browse). Each type of information of diverse content (research, educational, transport, financial, economic, industrial, managerial, medical, environmental, legal and other types) has its own specific technologies, semantic values and norms, forms of representation of the display; its requirements for the criteria of truth (fidelity to reality) and sincerity (fidelity to itself), accuracy, logic, purity, imagery, richness, accessibility and ease of perception of the text by the addressee, prompt reflection of facts, processes and phenomena. For example, the Yandex news service automatically processes and organizes databases of Russian and foreign mass media on forty topics, starting with sports and ending with politics, from 6,703 sources of various types: online media, newspapers, magazines, news agencies, radio, thematic sites. The picture of the day is updated online constantly and impartially.

The processing technology of a huge information mass creates conditions for manipulating individual static information blocks, provides their identification and formalized description for the convenience of automated storage, replenishment, updating and transmission of data. The movement of information flows is realized in humanmachine systems using symbolic symbols that undergo automated processing in the process of semantic (the semantic content of the text, its language correspondence, whether it is the language of an ethnos or a computer language), syntactic (especially quantitative characteristics of super-expressive parameters) and pragmatic (practical usefulness of information at a given time) analysis.

In our century, it is impossible to manage high-tech enterprises, organizations without computerized control systems, since this goes beyond the limits of biological possibilities. The person himself is also often represented as a complex information process-homeostasis, constantly balanced by the internal environment of the body and the external environment through the exchange of electronic discourse

\section{LITERATURE REWIEW}

In classical philosophies (despite the fact that it was Aristotle who gave the "communicative" definition of man as a "talking animal") it was about the spheres of being, apparently, did not include the communication sphere. Thus, the classical division into three spheres of existence: 
theoretical (mathematics, physics, metaphysics), practical (ethics, politics), and poetic (poetry, Economics), obviously, does not include a special area - the area of communication (See: Aristotle. Metaphysics. Book VI, Chapter one; Topeka, book VI, Chapter 6). It is from this dialogue that the so-called "old European tradition" originates, avoiding suspicious "sophisms", requiring an appeal to "things themselves" and seemingly assuming some access to the latter in their independence from their communicative discussion $[6,7]$.

The term itself, as well as the concept of overcoming - such a subject-oriented - "old European tradition" was proposed By N. Luhman [8].

In this study, we relied on the theoretical and methodological provisions of modern areas of linguistics and IC:

Cognitive linguistics: Demyankov [9]; Kibrik [10]; Kubryakova [11]; Popova and Sternin [12]; Slyshkin [13]; Langacker [14]; Fauconnier and Turner [15];

The theory of speech activity: Vygotsky [16]; Zhinkin [17]; Luria [18]; Fresse and Piaget [19];

Psycholinguistics and ethnopsycholinguistics: Galskova and Gez [20]; Karaulov [21]; Truspekova, Galimzhanova and Glaudinova [22]; Zulmi Ramdani, Rosleny Marliani and Agus Abdul Rahman [23]; Vassilenko (et al.) [24], Lyausheva, Karabulatova, Abregova, Mamisheva, Usova [25];

Linguoculturology: Aarushi Agarwal, Ajeet Patel, Tara Singh, Trayambak Tiwari, Anju Lata Singh [26]; Gali G.V., Fakhrutdinova, Gali A.I. [27]; Andreyeva, Korneyeva, Sakhibullina [28]; Zelenskaya, Golubtsov, Karabulatova, Kanon, Kasyanova [29]; Vereshchagin, Kostomarov [30];

Intercultural communication (IC): Akhmetova (et al) [31]; Bennett [32]; Bergelson [33]; Yoyo [34]; Gudkov [35]; Klyukanov [36]; Khaleeva [37]; Luchinskaya (et al.) [38]; Hall [39]; Porter and Samovar [40] et al.

The relevance of the stated topic stems from the need to describe the General framework of conceptual conceptualization of this phenomenon, which is a theoretical and cognitive task. Such a universal concept could be further specified by individual disciplines that distinguish in it their own, unique aspect or subject.

The epistemological interpretation of communicative processes carried out in the work meets the obvious possibilities of both their reductionist and universalist interpretation. On the one hand, we are dealing with narrow concepts of communication, and on the other hand, with extremely broad generalizations [41]. The proposed understanding of communication as a special kind of cognitive process provides an opportunity to go beyond the Scylla of reductionism and the Charybdis of universalism.

The concept of communication (from Latin communicatio), deeply rooted in European culture, languages and history, and initially pointed to a wide range of preferencesmessage, identity, communication, exchange, communication, treatment, community, Comes, presumably, from the Latin communicare (to do with each other, to do in common) and in the 15th century is approved in the English language. Its roots are much deeper. The Indo-European root man expresses the meaning of something in common, indicates a common sense of a word or behavior. Latin mundus has the meaning of public recompense for merit (indicates gifts, tribute, rituals of veneration of the dead). In Germanic languages from this root are formed the corresponding modern forms of meaning (eng.), Meinung, gemein (German.).
However, the modern scientific use of the term "communication" comes a little later thanks to Leo Leventhal in his (later used by Yu. Habermas) distinction between "authentic" and "instrumental" types of communication, where " genuine communication entails the formation of unity, socialization of internal experience" [42].

Such philosophical understanding of communication as a way of a certain "reconciliation" between the Ego and Others initially contrasts sharply with the emerging 40 years of "communicative theory" (mathematical theory of signal transmission and information), where communication appears as a functioning circuit (deanthropomorphized) units: source of information transmitter-encoder, message, channel, medium, receiver (decoder of the signal), the destination (destination) [43].

In such a "cybernetic" understanding of communication, the rigid sender/receiver distinction inherent in human communication with fundamentally different (in the recipient and the sender) types of access to the information that the message carries is blurred. Later, as a result of the development of the cybernetic concept, attempts are made to apply it to human communication itself. Thus, in the cybernetic interpretation of communication [44-48], the interest from the communicating poles (sender and receiver) gradually shifts to the field of media communication, i.e. to the channels of information dissemination themselves [49]. Depending on the adopted research program of language material study, various theoretical models of intercultural communication discourse and methods of discourse analysis were proposed. Linguistic studies of intercultural communication share a common vector of analysis through the prism of language, but it is necessary to recognize the presence of a significant number of scientific schools and many interpretations. The development and formation of intercultural communication was marked by interdisciplinarity and involvement of data and methods of various related disciplines.

\section{MATERIALS AND METHODS/ METHODOLOGY}

In this study, we relied on the theoretical and methodological provisions of modern linguistics and intercultural communication: cognitive linguistics (V.Z.Demyankov; A.A.Kibrik and others), theories of speech activity. Depending on the adopted research program of language material study, various theoretical models of intercultural communication discourse and methods of discourse analysis were proposed. Linguistic studies of intercultural communication share a common vector of analysis through the prism of language, but it is necessary to recognize the presence of a significant number of scientific schools and many interpretations. The development and formation of intercultural communication was marked by interdisciplinarity and involvement of data and methods of various related disciplines..I.Vygotsky; A.A.Leontyev; V.N. Luria; J.-P.Piaget), psycholinguistics and ethnopsycholinguistics (B.Z.Akhmetova; I.S.Karabulatova; Yu.N.Karaulov; I.I. Khaleeva), linguistic culturology (A.Wezhbitska V.P. Vereshchagin, V.G.Kostomarov), intercultural communication (Bergelson; V.V Krasnykh; A.A. Leontovich); discourse analysis (V.I.Karasik ; van Dijk), a systems approach (Alekseeva, Mishlanova; O'Connor), discourse analysis (van Dyck; Karasik; Fairclough; McDermott), corpus analysis 
methodologies (A.A.Kibrik; Mann, Thompson). Despite the fact that intercultural communication has long attracted the interest of researchers from different areas, there is still no work related to the integrated understanding of its theoretical and methodological foundations, there is no consensus on the subject of intercultural communication, methods of analysis, the study of the development of intercultural communication and intercultural specificity. This demonstrates the high relevance of comprehensive studies of intercultural communication, the integrative description of this phenomenon, the creation of a typology of the discourse of intercultural communication and the development of the foundations of its modelling.

The object of the research is the theory of communications, but not in all its broadest format, but in its socioepistemological aspect. Special attention is paid to cognitive conditions of communication-generalized symbolic media of communication. These include both universal means of communication dissemination (language, writing, printing and telecommunications, Internet) and symbolic means of achieving communicative success in specific areas of communication (social media, migration, globalization, etc.). At the same time, communication as an object of scientific research differs significantly from the "standard" subjects of scientific theorizing - moving bodies in physics, equifinally developing organisms in biology, transformations of atomic molecular bonds in chemistry in terms of its "measuring procedures" in space and time. In order to limit the object scope of the study, in addition to social space and social time, we introduce a special collective-personal dimension of communication, which allows us to take into account its specific meanings, which we call "social causations". Within this dimension, actions, statements, communications, and socially significant events are attributed a variety of types of "authorship" as their specific causes.

The subject of the study is the social and communicative content of the most important epistemic processes and the corresponding concepts of intercultural communication.

The hypothesis of our study is as follows. The very type of discourse has a deterministic influence on the nature of the nomination of the parameters of the subject, place and time of the event of intercultural communication. The main trend lies in a specific dynamic process that goes: 1) from interpersonal identity of the individual to social identity in the formation of intercultural competence; 2) from the usual locally-centered activity to the temporality of professional activity; 3) from a specific understanding of locus and temporality to an increase in the abstraction of localization and time.

The research material consisted of 29,219 discourse units (contexts and whole texts), representing the communication of representatives of different cultures / countries, obtained by the method of continuous sampling from texts of printed and electronic texts of mass communication, as well as personal texts, with a total volume of about 800 thousand words. The material is represented by publications in magazines and newspapers of different publishing, thematic and professional orientations, different genres (analytical article, news article, report, commentary, review, article, interview), Internet sites, blogs published from 1994 to 2018 The list of Russian and English sources includes more than 40 items.

The study used general scientific methods, including systems analysis and modeling, field methods, and statistical data processing methods (correlation analysis; statistical programs STATISTICA 6.0, Excel 2003, SPSS
10). Additionally, the sociological method of expert evaluation and the method of mapping were involved.

The linguistic research methods used in the work include component, definitional, comparative, contextual, semanticstylistic and compositional analysis, analysis of subjectrhematic articulation, as well as methods of cognitive linguistics (conceptual analysis, thesaurus model description method).

The following methods and theoretical approaches were applied in the study:

- methods and approaches of the General theory of communicative systems, social systems and mental systems $[50,51]$; - methods and approaches of the General theory of social systems used in the analysis of interaction systems, systems of organizations and functional systems [52]; logical and deductive methods of formalization of observation and communication processes; [53] methodology and approaches of second - order Cybernetics applied to the analysis of communicative understanding processes [54] - methods and approaches of constructivist psychology and linguistics [55] - methods and approaches of neo-Darwinian evolutionary theory (synthetic theory of evolution) applied to the analysis of society [56]

The design of the study includes an analysis of the macrostructures and microstructures of the discourse (van Dijk). The study of the macrostructure of the discourse was carried out on the material of 300 whole texts. To study the discourse microstructures, we have developed and applied the corpus discourse method (as a modification of the quantitative reference method), which consists in analysing the conceptual structure of an integrative concept in discourse as a set of texts on intercultural communication. Identification of theoretical-cognitive content of intercultural communication is associated with the following aspects of knowledge that makes possible new and enlarged concept of communication with theoretical fair value the below listed characteristics: first, it is the key problem of adequate understanding of the statements of Another, the reconstruction of which is difficult in conditions of inaccessibility of another's consciousness. Secondly, the problem of communication is associated with a fundamentally dual purpose of any communication, focused, on the one hand, on integration and mutual understanding, and on the other-on the information description of the subject of the statement. Thirdly, communication is considered in the study as based on the most important epistemological distinction of knowledge/ignorance, i.e. the knowledge of some information to one participant of communication and its unknown to another, which only provokes the formation of communication systems and the most diverse forms of sociality. In the fourth, intercultural communication is interpreted as bifurcated communication cognitive and communication regulatory and at the same time as structurally isomorphic to the process of cognition, as always appears rational choice (and in this sense cognition) between subject and object interpretations of a communication, a rational choice between the interpretation of statements aimed at maintaining cohesion (the message is known) and interpretation statements as focused on the message of the new and unknown.

Discursive analysis involves identifying the specifics of the representation of the parameters of an intercultural event at language levels, including lexical. Each parameter is determined by the grammatical function of the parameter unit in the sentence: The subject is subject and complement, Place is the circumstance of place, Time is the circumstance 
of time. Each unit is recorded in the database and is marked by semantics and type of discourse. Aggregate data is analyzed by the field method (the nuclear-peripheral composition of each parameter is determined by nominations classes), the key classes of nominations of each parameter and their interrelationship are identified.

The study of the construction of intercultural communication in electronic media allows us to conclude that in Internet discussions on intercultural communication and interethnic conflicts, there is a whole range of different discourses, ranging from ultra-nationalist to liberal. Radical discourses are characterized by sharpness and categorical judgments, a claim to represent the opinion of the ethnic majority, the use of derogatory words and ethnic nicknames. Among radical discourses there are often discourses of incorrect behavior of ethnic minorities provoking violence against themselves ("discourse of the enemy", "discourse of sexual aggression"), corruption / impotence of power and law enforcement agencies ("discourse of weakness of the state"), as well as biased display of the state of interethnic relations in the media ("discourse of media lies").

Considering the elaboration and history of this concept, we are forced to distinguish between two separate stories: the history of the term, which changed its meanings (the history of semantics), and the history of the concept itself, which is not fixed unambiguously in the form of a term, but shows some historical content invariance. The latter implies the presence of the modern meaning of the word in the past conceptualization of this phenomenon and its reproduction. Thus consideration of such evolution of the senses fixed syntactically, in the form of a word, quite can assume work with the different concepts United only in an external way.

\section{DISCUSSION}

Present the materials, methods, survey, questionnaire etc used for the study. Author should explain whether this study is experimental, or review study, or simulation based, or survey based. Discuss software, hardware's used during study with their brand names. Mention all research conditions, assumptions, theories followed. This section should be easy enough for any reader to repeat the study under similar conditions. Appeal to the history of intercultural communication indicates that the formation of intercultural communication as an independent discipline occurred for a long time. The interrelation of culture, activity and language was noted in the works of V. von Humboldt ("Each language describes around the people to which it belongs, a circle from which it can be reached only if you enter another circle"), which emphasized not only the complexity of intercultural boundaries, but also their principled avoid ability (Briefe Von Alexander Von Humboldt A.).

Inter-ethnic conflicts occupy a special place. The statistics given by the American researcher A. Wimmer show that during the period from 1945 to 2002 the number of interethnic confrontations (not counting civil wars) increased more than six times and amounted to more than 180 [57].

When analyzing the historical aspect of the theoretical foundations of intercultural communication, a shift of scientific paradigms is clearly seen (Tables 1 and 2):

Table 1 Stages of development of intercultural communication

\begin{tabular}{|l|l|l|l|l|}
\hline Social & Interpretative & Dialectic & Ethnographic & Critical \\
\hline
\end{tabular}

We can characterize each level according to six basic criteria. These criteria demonstrate sustainability, which makes it possible to structure the history of the exhaustion of intercultural communication.

Table 2 Social level

\begin{tabular}{|c|c|c|c|c|c|}
\hline Personalities & Postulates & Objectives & Methods & Benefits & Disadvantages \\
\hline $\begin{array}{l}\text { M. Bennet, A. } \\
\text { Giddens, R. } \\
\text { Porter, L. } \\
\text { Samovar }\end{array}$ & $\begin{array}{c}\text { Researchers } \\
\text { describe external } \\
\text { reality; human } \\
\text { behavior is } \\
\text { predictable }\end{array}$ & $\begin{array}{c}\text { Describe and } \\
\text { predict behavior }\end{array}$ & $\begin{array}{c}\text { Quantitative } \\
\text { methods: } \\
\text { collection and } \\
\text { quantitative data } \\
\text { processing (most } \\
\text { often } \\
\text { questionnaires) }\end{array}$ & $\begin{array}{l}\text { High level of } \\
\text { data reliability; } \\
\text { minimization of } \\
\text { subjectivity of } \\
\text { conclusions; } \\
\text { possibility of } \\
\text { long } \\
\text { measurements }\end{array}$ & $\begin{array}{c}\text { Lack of } \\
\text { information on } \\
\text { situational } \\
\text { context; limited } \\
\text { conclusions }\end{array}$ \\
\hline
\end{tabular}

Discourse as an integrative object (verbally mediated activity in a special field) involves the accumulation of all knowledge and ideas about a special object (in this case, intercultural communication), and the entire body of knowledge about an object is described as a concept. At the same time, it is not based on an abstract body of knowledge, conceptualization is based on mental processes that are aimed at the formation of new knowledge and the transformation of personality. The mechanism of personal development, therefore, is a mechanism of conceptual integration, the restructuring of the internal categorical system, the integration of new constructs into the system. 
Table 3 Interpretative dialectic ethnographic levels in intercultural communication

\begin{tabular}{|c|c|c|c|c|c|}
\hline Personalities & Postulates & Objectives & Methods & Benefits & Disadvantages \\
\hline $\begin{array}{l}\text { M.Mid, B.Rut, } \\
\text { A.P.SadokhinM } \\
\text {.Fuko, } \\
\text { N.Fearklo }\end{array}$ & $\begin{array}{l}\text { Reality is } \\
\text { subjective; } \\
\text { context in } \\
\text { communication is } \\
\text { important; } \\
\text { investigates } \\
\text { power relations } \\
\text { in } \\
\text { communication } \\
\text { and how they } \\
\text { influence cultural } \\
\text { communication }\end{array}$ & $\begin{array}{l}\text { Understand and } \\
\text { describe human } \\
\text { nature, affect the } \\
\text { lives of } \\
\text { communicants }\end{array}$ & $\begin{array}{c}\text { Qualitative: } \\
\text { rhetorical, } \\
\text { stylistic analysis; } \\
\text { artifact detection } \\
\text { and analysis }\end{array}$ & $\begin{array}{l}\text { Getting a realistic } \\
\text { picture of the } \\
\text { phenomenon; the } \\
\text { use of a holistic } \\
\text { approach to the } \\
\text { phenomenon } \\
\text { under study; use } \\
\text { of descriptions } \\
\text { based on primary } \\
\text { and unstructured } \\
\text { data }\end{array}$ & $\begin{array}{c}\text { The difficulty of } \\
\text { explaining the } \\
\text { differences } \\
\text { between quality } \\
\text { and quantity of } \\
\text { information; lack } \\
\text { of complete } \\
\text { objectivity and } \\
\text { reliability of } \\
\text { conclusions }\end{array}$ \\
\hline
\end{tabular}

The trend in the formation of intercultural competence is in the dynamics from the interpersonal identity of the individual to the social, from the ordinary locally-centered activity towards the temporality of the professional activity, as well as increasing the abstractness of localization and time. Statistical processing of linguistic parameters reveals a direct dependence of the intercultural competence of the individual on the experience of social interaction.

Table 4 Dialectical level in intercultural communication

\begin{tabular}{|c|c|c|c|c|c|}
\hline Personalities & Postulates & Objectives & Methods & Benefits & Disadvantages \\
\hline $\begin{array}{l}\text { I.E. Klyukanov, } \\
\text { N. Nishida, R. } \\
\text { and S. Skollona, } \\
\text { R. Waizman }\end{array}$ & $\begin{array}{c}\text { Intercultural } \\
\text { communication is } \\
\text { conditioned both } \\
\text { culturally and } \\
\text { personally; } \\
\text { communication is } \\
\text { both static and } \\
\text { dynamic; time is } \\
\text { dialectical }\end{array}$ & $\begin{array}{l}\text { Appeal to the } \\
\text { theory of } \\
\text { discourse } \\
\text { actualizes the } \\
\text { search for } \\
\text { relevant methods } \\
\text { of analysis of } \\
\text { intercultural } \\
\text { communication, }\end{array}$ & $\begin{array}{l}\text { The current stage } \\
\text { of development } \\
\text { of intercultural } \\
\text { communication } \\
\text { focuses on } \\
\text { discourse } \\
\text { analysis and } \\
\text { conceptual } \\
\text { analysis }\end{array}$ & $\begin{array}{l}\text { The integration } \\
\text { of cultural } \\
\text { traditions - the } \\
\text { conjugation of } \\
\text { the achievements } \\
\text { of the western } \\
\text { and national } \\
\text { schools - has not } \\
\text { only the greatest } \\
\text { heuristic } \\
\text { potential, but also } \\
\text { corresponds to } \\
\text { the essence and } \\
\text { spirit of } \\
\text { intercultural } \\
\text { communication, } \\
\text { which by } \\
\text { definition is } \\
\text { intercultural. }\end{array}$ & \\
\hline
\end{tabular}

In the 1940s intercultural communication receives the status of an empirical social / functional discipline that classifies cultural contacts and makes recommendations for resolving intercultural conflicts. In this paradigm, the object of intercultural communication was defined in the sociological aspect. 
The next critical / interpretive paradigm in the evolution of intercultural communication was accompanied by an increase in interdisciplinary connections and a consistent complication of the object in which researchers sought to explore the role of the communication context and the role of communicators [39].

The modern dialectical paradigm recognizes the complexity of intercultural communication, its complex integrative nature, and is engaged in the search for an adequate object and methods for its study.

Paradigm analysis speaks of the inherent intercultural communication of the search for a new object that can comprehensively reflect new interdisciplinary trends. Since the successive paradigm shift entails a qualitative complication of the object in each paradigm, but it does not solve the problems of the integrative description of the discipline, a new methodology is required that can take into account not only intra-paradigm, but also inter-paradigm interrelations. It is the complexity and integration of the object that gives intercultural communication a great heuristic potential.

In this paper, the main established schools of intercultural research are highlighted: Western and Russian. The traditional functional approach to the object dominates in the works of the western school; therefore, the studies and their results are fragmentary in relation to a complex object of intercultural communication. In the domestic school, in relation to complex integrated objects, the activity approach and the theory of discourse are used, but the object of intercultural communication did not fall into the focus of attention of researchers. The integration of cultural traditions - the conjugation of the achievements of the western and national schools - has not only the greatest heuristic potential, but also corresponds to the essence and spirit of intercultural communication, which by definition is intercultural [58].

So, R. Jacobson believed that the study of communication should be carried out within the framework of such overlapping areas as sociolinguistics, social anthropology along with economics, ethnolinguistics, semiotics [59].

In the course of the analytical review of intercultural communication, it was revealed that the research methods of intercultural communication reflect the paradigms of its development. In the traditional / functional direction of intercultural communication studies, quantitative methods have been developed for analyzing the intercultural competence of an individual in adapting to a multicultural environment - tools that have become widespread due to the high verifiability of quantitative data. The critical / interpretive paradigm of intercultural communication development focuses on qualitative methods of analysis (rhetorical, stylistic analysis, text analysis) and takes into account the dynamic and personal aspects of intercultural communication. Appeal to the theory of discourse actualizes the search for relevant methods of analysis of intercultural communication, and the current stage of development of intercultural communication focuses on discourse analysis and conceptual analysis.

\section{RESULTS}

Provide logical, and scientific analysis of findings of the study. Present evidences to support your analysis by citing work of earlier researchers or existing theories. Intercultural communication, interdisciplinary and integrative in nature, is an object that can be adequately studied only from the standpoint of cognitive-discursive theory. The greatest heuristic potential of the study of intercultural communication is possessed by activity theories, which treat the discourse as verbally mediated activity in a special field. Within the framework of the activity theory, the cognitive mechanism is the mechanism of development of the linguistic personality, one of the options for describing which is the theory of conceptual integration.

All categories of discourse theory are modeled in a matrix manner, taking into account the specificity of the sign and sign activity, for example:

I. Discourse

Discourse as a landmark activity appears in four representations:

1. activity (interaction)

2. process (change of activity phases)

3. result of activity (product, set of texts on a given topic)

4. a set of signs (sign system), semiotic processing of a sign representing an activity (for example, material culture, cultural code).

Ii. Intercultural communication

1. Intercultural communication - the activities of people at the crossroads of cultural borders (both physical and non-physical)

2. Intercultural communication - the transformation of the individual, the formation of a multicultural personality

3. Intercultural communication - a set of texts generated in the course of intercultural communication, as well as texts on the topic of intercultural communication, ordered from naive to scientific depending on the level of professional competence

4. Intercultural communication - the system of signs (conceptual apparatus, terminology).

The isomorphism of the matrix representation of the definitions of key concepts makes it possible to clarify a discussion point for intercultural communication: can intercultural communication be considered if it is not communication between representatives of different nationalities? It is obvious that within the framework of discourse there is a broadening of the understanding of Intercultural communication to the framework of communication between people of different competencies for example, in the social differentiation of communication, intercorporate, intergenerational, intergender will be related to intercultural communication [60].

Coverage of the cross-cultural communication issues in the light of discourse theory, namely, addressing the integrative property to the provisions of the theory of personality development, the theory of linguistic personality, activity theory with selected phases of internal structure and, in general, discourse as an activity and system phenomenon, creates prerequisites for modeling intercultural communication activities [61]. Based on the internal structure of discourse as an activity, we can get a monoparadigmatic model of discourse of intercultural communication, presented in models of personal development in phases to overcome intercultural barriers. Based on the criterion of interaction with the Other, the models distinguished are also monoparadigm and contradictory, especially empirically.

The model of an integrating type is built on the basis of the activity nature of the discourse of subjects in the special field of intercultural communication. The work takes into account the following specific features of the intercultural communication discourse: 
a. phases of personal development (conceptualization phases, stages of activity);

b. the polyprofessionalism of the linguistic personality in the special conditions of intercultural communication;

c. the hierarchy of the discourse of the special sphere (from the naive to the scientific);

d. four-part interaction with the Other according to the principles of complementarity and counter-dictatorship.

Thus, the discursive theory of intercultural communication refers to an integrative model of intercultural communication, taking into account professional competence, or a poly-professional language personality [62].

The proposed discourse model postulates such discourse properties as integrativity (and fragmentation), hierarchy (and diffusivity), heterogeneity (and homogeneity), complementarity (and contradictivity).

The integrative model of the discourse of intercultural communication not only repeats the phases of personality development, is structured according to the levels of personality development, repeats the development phases of a sign in a discourse, but also repeats the structure of activity with motivational, approximate, implementing and controlling steps. At the same time, the training type of discourse in the model of the discourse of intercultural communication is more associated with the motivational stage, the tourist - with orientation, professional - with implementing (production), special - with controlling (see Table 5).

Table 5 The structure of the discourse of intercultural communication

\begin{tabular}{|c|c|c|c|}
\hline Discourse & $\begin{array}{c}\text { Level of Professional } \\
\text { Competence of } \\
\text { Intercultural } \\
\text { Communication }\end{array}$ & $\begin{array}{c}\text { Level of Professional } \\
\text { Competence of } \\
\text { Intercultural } \\
\text { Communication }\end{array}$ & $\begin{array}{c}\text { Level of Professional } \\
\text { Competence of } \\
\text { Intercultural } \\
\text { Communication }\end{array}$ \\
\hline $\begin{array}{c}\text { Professional } \\
\text { Practical }\end{array}$ & Tourist personal & Professional non-special & Professional special \\
\hline $\begin{array}{c}\text { Practical } \\
\text { Naive }\end{array}$ & Learning & Teaching advanced & Learning immersed \\
\hline
\end{tabular}

The integrative model of discourse is not in the systemstructural way of integration (as is most often represented in the modeling processes), but in the volumetric one. Consequently, the graphically integrative model of discourse, including the discourse of intercultural communication, is presented in the form of a cyclical (taking into account phaseness) graph, rather than a stepped graph. The discourse of intercultural communication and its corresponding model take into account the shift of activities as a condition for the development of personality.

The first, learning type of discourse intercultural communication includes the spectrum of interaction of individuals when learning a foreign language. Studying a foreign language, students are attached to a different culture, and "language teaching is always intercultural communication" [63]. Within the framework of the competence-based approach to learning foreign languages, the concept of "communicative competence" goes beyond the framework of linguistic competence and is included in the structure of intercultural competence. In methodical terms, this means a shift from mechanical learning to deep forms of language expression. Researchers of teaching a foreign language as a specialty, or teaching a special purpose language (ESP) came closest to realizing the need for an integrative concept of a foreign language teaching methodology. And if in the first case, an understanding of the problem is explained by the obvious need for "appropriating" foreign language and foreign culture communication, then in the second case, overcoming the traditional view of a foreign language solely as a necessary condition for obtaining a future profession (especially nonphilological profile) occurs only recently. So, the researchers point out the need for a poly-professional activity of a specialist, when he needs not only to do his job (goal in MC conditions), but also, at the same time, to act as an interpreter (to himself), a teacher, a librarian, an organizer of a workplace. Individuals must constantly continue to form within themselves a "mediator" - the mediator of cultural communication. Such a point of view corresponds to the cultural state of communication and at the same time enables communicators to react responsibly and naturally to the sociocultural parameters of communication.

Despite the fact that at the professional level, tourist / personal type of discourse is the most widespread type of intercultural contacts, the studies of this discursive type are few. In the literature, the subjects of intercultural interaction are delimited: tourist and temporarily staying. The tourist faces intercultural action to increase the "attractiveness" of current life, without changing it. A temporarily resident, on the contrary, seeks influence on society. Practical manuals and guides for tourists and temporarily staying interdiscursiveness of this social sphere: institutions such as the immigration service, customs, international organizations demonstrate the relationship of this area with a special professional discourse, on the one hand, and on the other hand, the transport service, medicine, trade involves professional communication and emphasizes the practical nature of communication [64].

General properties of a tourist's discourse: 1) "capsularity", peculiar to all levels and the entire space of tourist discourse when choosing a place for a trip; 2) standardization (transport, place of residence, list of attractions, reference books, food); 3) the destination of objects for tourists (traditions of the country, place of residence). The intercultural basis of tourism is confirmed, firstly, by the multiplicity of forms of tourist discourse (adventure, ecotourism, mass, resort, hiking, trips to the honeymoon), and secondly, by the symbolic character of modeling tourist experience (knowledge). 
Professional non-special type includes the range of communication of non-specialists in the field of intercultural communication (international business). Conventionally, this type of activity can be divided into two classes: a) retraining of specialists for work abroad; b) professionally integrated teaching of a foreign language, whereby the intercultural component is meant a parallel native foreign language sphere of professional activity.

The first class of activity is designed for short-term effectiveness, the effectiveness of the performance of work during training through assimilators, case methods, roleplaying games. With all its advantages, which primarily include the maintenance of competence in professional qualifications, training does not pursue the goal of selfreflection and the development of self-motivation.

\section{CONCLUSION}

Indeed, empirical research data confirms that the majority of non-professional intercultural communication professionals believe that intercultural competence is a natural quality (like language skills), that individual personality characteristics predetermine intercultural competence (for example, a successful organizer everywhere manifests his organizational skills) and that short-term training solves long-term challenges.

In the conditions of a communicative situation, the role of a language depends on the work of universal cognitive mechanisms, culture-specific knowledge, ways of organizing information and manifests itself in three possible options:

1) For one of the interlocutors, the language of communication can be native, and for another (others) foreign.

2) Interlocutors choose an intermediary language, but for all participants of communication it is foreign (for example, English).

3) The interlocutors communicate through an interpreter, whose task is to ensure effective communication.

Common to all variants of the situation is the action of linguistic mechanisms, since each of the participants, including the translator, relies first and foremost on his culture-specific linguistic picture of the world. The translator and those who communicate in the intermediate language have a secondary linguistic picture of the world, however, it is not isolated from the primary one formed in the native culture. Both pictures of the world interact, but the degree of formation of the secondary linguistic picture of the world directly affects the form and content of the verbal message generated in a foreign language. Therefore, an appeal to the study of linguistic foundations of intercultural communication seems relevant.

\section{LIMITATION AND STUDY FORWARD}

The context of globalization places new demands on intercultural communication, which takes place in both real and virtual discourses.

If the rules of intercultural communication in real life are studied, compiled over many centuries, the rules of intercultural communication in the virtual world are just beginning to take shape.
This process, participants and observers of which we are, allows the modern researcher to look into the process of construction and destruction of the next "tower of Babel". This space opens up truly unlimited possibilities both in terms of the volume of information and its influence on the linguistic personality of modern person.

Perhaps in the not-too-distant future we will encounter more closely the phenomenon of a planetary digital language personality that will reveal traits of both artificial intelligence and natural language.

We can assume that the very nature of intercultural communication will undergo significant changes.

\section{ACKNOWLEDGMENT}

The authors performed this work within the framework of the grant RFBR 17-04-00607OGN. This paper was financially supported by Ministry of Education and Science of Russian Federation on the program to improve the competitiveness of Peoples' Friendship University of Russia (PFUR University, RUDN-university) among the worlds leading research and education centres in the 2016-2020. This publication was supported by the Ministry of Education and Science of Russian Federation (the Agreement number 02.A03.21.0008).

\section{REFERENCES}

[1] K.-O. Apel, The transformation of philosophy, 2001.

[2] Y. Habermas, Moral consciousness and communicative action, 2000.

[3] U. Altermatt, Ethnonationalism in Europe, 2000.

[4] D. Bell, The coming post-industrial society. Experience of social forecasting, 1999.

[5] J. Habermas, Technology and Science as "Ideology", 1971.

[6] D. Baecker, Kommunikation. Reklam. Suhrkamp, 2005.

[7] D. Baecker, Form und Formen der Kommunikation. Suhkamp, 2005.

[8] N. Luhmann, Gesellschaftsstruktur und Semantik: Studien zur Wissenssoziologie der modernen Gesellschaft. Suhrkamp, 1994.

[9] V.Z. Demyankov, Pragmatics of communication and cognition. Cognitive studies of language, Cognition and communication in linguistic research 29 (2017) 5563.

[10] A.A. Kibrik, Reference in discourse, Oxford University Press, 2011. 
[11] E.S. Kubryakova, Language and knowledge: on the way of getting knowledge about language: parts of speech from cognitive point of view. The role of language in the knowledge of the world, 2004.

[12] Z.D. Popova, I.A. Sternin, Cognitive linguistics, AST, East-West, 2007.

[13] G.G. Slyshkin, From text to symbol: linguistic and cultural concepts of case texts in consciousness and discourse, Academia, 2000.

[14] R. Langacker, Conceptual grouping and pronominal anaphora, in: Studies in anaphora, 1996, pp. 333-378.

[15] G. Fauconnier, M. Turner, The Way We Think: Conceptual Blending and the Mind's Hidden Complexities, Basic Books, 2002.

[16] L.S. Vygotsky, Questions of theory and history of psychology, Collected works in 6 vols., Pedagogy 1 (1982).

[17] N.I. Zhinkin, Language-speech-creativity: 1. on semiotics, psycholinguistics, poetics, Selected works, Labyrinth, 1998.

[18] A.R. Luria, Fundamentals of neuropsychology, Academy, 2003.

[19] J.P. Fresse, Traite de psychologie expérimentale, 4, 1973.

[20] N.D. Galskova, N.I. Gez, Theory of teaching foreign languages. Linguodidactics and methodology, Academy, 2006.

[21] Yu.N. Karaulov, Russian language and language personality, URSS, 2004.

[22] Kh.Kh. Truspekova, A.S. Galimzhanova, M.B. Glaudinova, National identity and architecture of NurSultan, Humanities \& Social Sciences Review 7(5) (2019). DOI: https://doi.org/10.18510/hssr.2019.7542

[23] Zulmi Ramdani, Rosleny Marliani, Agus Abdul Rahman, The individual work performance scale: A psychometric study and its application for employee performance, Humanities \& Social Sciences Review 7(5) (2019) 405-414.

[24] A.P. Vassilenko, I.S. Karabulatova, E.N. Vasilishina, R.A. Tukaeva, V.V. Barabash, The conceptual sphere of fiction in the Russian and English world picture, Opción 34(85) (2018) 825-839.

[25] S.A. Lyausheva, I.S. Karabulatova, Zh.O. Abregova, Z.A. Mamisheva, L.V. Usova, Problems of Innovative Development in the Modern Ethno-cultural Environment, Astra Salvensis 6(12) (2018) 745-751.

[26] Aarushi Agarwal, Ajeet Patel, Tara Singh, Trayambak Tiwari, Anju Lata Singh, A review on dissociative perspective of attention and consciousness,
Humanities \& Social Sciences Review 7(5) (2019) 516521.

[27] G.V. Gali, A.V. Fakhrutdinova, A.I. Gali, Foreign language teaching to linguistically gifted students: communicative competence, Humanities \& Social Sciences Review 7(4) (2019) 394-398.

[28] Ye.A. Andreyeva, I.G. Korneva, K.A. Sakhibullina, Values and anti-values in figurative phraseological units in the Russian and German languages, Humanities \& Social Sciences Review 7(4) (2019) 427-432.

[29] V.V. Zelenskaya, S.A. Golubtsov, I.S. Karabulatova, I.A. Kanon, Z.S. Kasyanova, Innovative Discourse in the Formation of a Modern Ethno-Cultural Environment, Astra Salvensis 6(12) (2018) 753-766.

[30] E.M. Vereshchagin, V.G. Kostomarov, Language and culture, Indrik, 2005.

[31] B.Z. Akhmetova, B.N. Kaliev, I.S. Karabulatova, E.N. Bazalina, L.V. Skachkova, The Cognitive Analysis of Turkic Ethnonyms "Kazakh" and "Tatar" in the Linguistic Space of the Russian frontier in the context of ethno-confessional dialogue, Opción 34(85) (2018) 1509-1526.

[32] W.L. Bennett, The Uncivic culture: Communication, Identity, and the rise of lifestyle politics, Political Science and Politics 31(4) (1998).

[33] M.B. Bergelson, Pragmatic and socio-cultural motivation of the language form, Dissertation of doctor of Philology, MSU, 2005.

[34] Yoyo, Neo-Patriarchy and the problem of the Arab crisis: A critical study on Hisham Sharabi's Works, Humanities \& Social Sciences Reviews, 7(4) (2019) 1004-1010. DOI:

https://doi.org/10.18510/hssr.2019.74137

[35] D.B. Gudkov, Codes of culture and the system of natural language, Russian studies without borders 1 (2017) 64-74.

[36] I.E. Klyukanov, Dynamics of intercultural communication: a system-semiotic study, 1998.

[37] I.I. Khaleeva, Fundamentals of the theory of teaching foreign language comprehension: training of translators, Higher school, 1989.

[38] E.N. Luchinskaya, I.S. Karabulatova, V.I. Tkhorik, V.V. Zelenskaya, C.A. Golubtsov, New aspects of intercultural communication discourse modeling in the context of globalization and migration, Opción 34(85) (2018) 789-800.

[39] E.T. Hall, Beyond Culture, Anchor Books, 1981.

[40] R. Porter, L. Samovar, Communication between Cultures, Wadsworth Publishing Company, 1995.

[41] W.R. Ashby, An Introduction to Cybernetics, 1956. 
[42] L. Loewenthal, Humanität und Kommunikation, Literatur und Massenkultur, Suhrkamp, 1980

[43] C.E. Shannon, W. Weaver, The Mathematical Theory of Communication, University of Illinois Press, 1949.

[44] W.R. Ashby, Requisite Variety and its Implications for the Control of Complex System, Cybernetica 1 (1958).

[45] H. Foerster, Cybernetics of Cybernetics: The Control of Control and the Communication of Communication, Future Systems, 1995.

[46] N.K. Hayles, Boundary Disputes: Homeostasis, Reflexivity, and the Foundations of Cybernetics, Configurations 3 (1994).

[47] G.E. Lasker, Applied Systems and Cybernetics, 1981.

[48] G. Günter, Cognition and Volition: a Contribution to a Cybernetic Theory of Subjectivity, Beiträge zur Grundlegung einer operationsfähigen Dialektik, 1979.

[49] F. Heider, Ding und Medium, 2005.

[50] E. von Weizsacker, Offene Systeme: Beitrage zur Zeilstruktur von Information, Entropie und Evolution, Stuttgart, 1974.

[51] G. Roth, Biological Systems Theory and the Problem of Reductionism, Self-organizing Systems: An Interdisciplinary Approach, 1990.

[52] J. Eugene, Aspects de la theorie generale des systemes: Une recherche des universaux, 1981.

[53] G. Spencer-Brown, Laws of Form, 1979.

[54] H. Foerster, Understanding Understanding, Essays on Cybernetics and Cognition, 2010.

[55] G. Bateson, Ecology of mind, Sense, 2000.

[56] R. Dawkins, Selfish gene, 1993.

[57] A. Wimmer, Introduction: Facing ethnic conflicts, in: Facing Ethnic Conflicts. Towards a New Realism, Rowman and Littlefield, 2004.

[58] I. Karabulatova, M. Patieva, M. Seidina, A. Podkopaeva, V. Kushnirenko, G. Niyazova, Ethnosociocultural deviations in the educational environment of the modern Eurasian Higher Education Institution as a reflection of transcultural globalization factors, Man in India 97(23) (2017) 95-103.

[59] R. Jacobson, Speech communication, Selected Works, 1985.

[60] Y. Ebzeeva, S. Sheipak, L. Gishkayeva, D. Nakisbaev, I. Karabulatova, N. Dubinina, The problems of formation of the modern elitist language personality in the age of globalization and migrations, Man in India 97(23) (2017) 321-328.

[61] I.S. Karabulatova, S.A. Lyausheva, A.A. Nagoy, A.A. Rozhkov, E.S. Studenikina, The problem of "OUR/OTHERS" in the discourse of intercultural communication and the new challenges of globalization and migration, Interciencia Journal 43(8) (2018) 177192.

[62] G. Rakisheva, I. Karabulatova, A. Abibulaeva, Ethno-sociocultural deviations in the educational environment of the modern eurasian higher education institution as a reflection of transcultural globalization factors, Man in India 97(23) (2017) 115-131.

[63] Y.N. Ebzeeva, I.S. Karabulatova, D.A. Nakisbaev, The Problems of Transformation of the Personal Identity in a Modern Migrant, Astra Salvensis 11(1) (2018) 729738.

[64] Y. Ebzeeva, I. Karabulatova, Transcultural language personality: statement of the problem and conceptual space, Man in India 97(23) (2017) 255-262. 